\title{
Endothelium derived relaxation factors reduce sulfur dioxide-induced aortic relaxation
}

\author{
Omar A. M. Al-Habib ${ }^{1}$, Abbas B. Q. Salihi ${ }^{2}$ \\ ${ }^{1}$ Biology Department, Faculty of Science, University of Zakho, Duhok, Iraq \\ ${ }^{2}$ Biology Department, College of Science, University of Salahaddin, Erbil, Iraq \\ Email: abbas.salihi@uni-sci.org
}

Received 30 July 2013; revised 30 August 2013; accepted 6 September 2013

Copyright (C) 2013 Omar A. M. Al-Habib, Abbas B. Q. Salihi. This is an open access article distributed under the Creative Commons Attribution License, which permits unrestricted use, distribution, and reproduction in any medium, provided the original work is properly cited.

\begin{abstract}
The endothelium plays a key role in the control of vascular patency and tone. Thus, the main objective of the study was to determine the role of endothelium and its derived relaxation factors in mediating relaxation of rat thoracic aorta, in response to sulfur dioxide $\left(\mathrm{SO}_{2}\right)$ derivatives " $1: 3 \mathrm{M} / \mathrm{M}$ sodium bisulfite $\left(\mathrm{NaHSO}_{3}\right)$ and sodium sulfite $\left(\mathrm{Na}_{2} \mathrm{SO}_{3}\right)$ ” using PowerLab tissue bath system. Endothelial denudation enhanced relaxation responses of $\mathrm{SO}_{2}$ derivatives with an $\mathrm{IC}_{50}$ of $6.11 \mathrm{mM}$ as compared to control rings with an $\mathrm{IC}_{50}$ of $6.21 \mathrm{mM}$, as well as the maximum relaxation $\left(E_{\max }\right)$ was increased from $62.026 \% \pm 6.527 \%$ to $83.13 \% \pm 14.755 \%$. Furthermore, the relaxation responses to $\mathrm{SO}_{2}$ derivatives in aortic rings were significantly enhanced by indomethacin, clotrimazole and methylene blue with $\mathrm{IC}_{50}$ 's of $4.8 \mathrm{mM}, 5.33 \mathrm{mM}$ and $4.01 \mathrm{mM}$, and $E_{\max }$ were raised to $101.1 \% \pm$ $6.537 \%, 66.92 \pm 7.538$ and $104.68 \pm 3.575$, respectively. Meanwhile, L-NAME did not alter dose-dependent relaxation of $\mathrm{SO}_{2}$ derivatives in comparison to control aortic rings. The results of this study had shown that endothelium denudation and blocking of endothelium derived-relaxation factors enhanced vasodilator effect of $\mathrm{SO}_{2}$; this may clarify the role of endothelium in the vasodilatory mechanism of $\mathrm{SO}_{2}$.
\end{abstract}

Keywords: Sulfur Dioxide; Endothelium; Endothelium Derived-Relaxation Factors; Organ Bath; PowerLab System; Aorta

\section{INTRODUCTION}

The vascular endothelium is strategically located at the interface between the circulating blood and vessel wall, providing a permeability barrier to the movement of cell metabolites and nutrients, while allowing the transfer of electrical signals within the intact tissue [1]. Endothelial cells synthesize and release various factors that modulate in short terms vascular tone. The vasoactive factors include relaxing substances, prostaglandin $\mathrm{I}_{2}\left(\mathrm{PGI}_{2}\right), \mathrm{NO}$, endothelium-derived hyperpolarizing factors (EDHF), Cnatriuretic peptide, and contracting substances, such as, thromboxane $\mathrm{A}_{2}\left(\mathrm{TXA}_{2}\right)$, endothelin-1, angiotensin II, superoxide anion [2].

Sulfur dioxide is a common air pollutant released into the atmosphere from the combustion of fossil fuel [3]. Inhaled $\mathrm{SO}_{2}$ is hydrated to produce sulfurous acid in the respiratory tract, which subsequently dissociates to form its derivatives, bisulfite and sulfite $(1: 3 \mathrm{M} / \mathrm{M}$ in neutral fluid). The derivatives can be absorbed into the blood or other body fluids [4]. In addition, bisulfite/sulfite enters the body via foods, beverages and drugs, because of sulfiting agents, such as $\mathrm{SO}_{2}$, metabisulfite, $\mathrm{NaHSO}_{3}$, and $\mathrm{Na}_{2} \mathrm{SO}_{3}$ [5]. Endogenously produced gaseous $\mathrm{SO}_{2}$ is hypothesized to fulfill a physiological role in regulating cardiovascular function, distinctive from its toxicological effects [6]. Vasodilatory effect of $\mathrm{SO}_{2}$ derivatives on isolated rat aortic rings first reported by Meng and his team in 2005 , although the exact mechanism of vasodilatation is still unknown [7].

Sulfur dioxide could relax vascular smooth muscle cells (VSMCs), and the mechanism might be associated with the activation of calcium $\left(\mathrm{Ca}^{++}\right)$channels and ATPdependent potassium $\left(\mathrm{K}_{\mathrm{ATP}}\right)$ channels [8]. Further more, [9] found that $\mathrm{SO}_{2}$ derivatives can alter cell's excitability by increasing the firing frequency of potassium $\left(\mathrm{K}^{+}\right)$ channels in hippocampal neurons and ventricular myocytes. While, [10] showed that $\mathrm{SO}_{2}$ derivatives significantly enhanced voltage-gated sodium channels in a concentration-dependent manner in isolated adult rat cardiomyocytes. On the other hand, [11] recently found that 
rat blood pressure could be lowered by $\mathrm{SO}_{2}$ and its derivatives, also they were demonstrated that the vasorelaxant effect of $\mathrm{SO}_{2}$ at basal and low concentrations might be mediated by NO and/or cGMP pathway. NO mediates vasorelaxation by increasing the cellular cGMP level and/or stimulating $\mathrm{Ca}^{++}$-dependent $\mathrm{K}^{+}$channels $\left(\mathrm{K}_{\mathrm{Ca}}\right)$ in VSMCs. So the mechanism of $\mathrm{SO}_{2}$-induced vasorelaxation should partially involve the contribution of $\mathrm{K}_{\mathrm{Ca}}$ channels. Because there is only little information about the mechanism of action of $\mathrm{SO}_{2}$, therefore, this study is one of our attempts to detect the role of endothelium in the relaxatory pathway of $\mathrm{SO}_{2}$.

\section{MATERIALS AND METHODS}

The animal experimental procedures conformed to the "Guide for the Care and Use of Laboratory Animals" published by the National Institutes of Health (NIH) in the United States and was approved by the Animal Research Committee of Zakho University. Adult male Wistar rats (Rattus norvegicus) were used for this study. The animals were kept under standard laboratory conditions. After anaesthetizing, the chest cavity was opened, after removal of excess tissue and fat, thoracic aorta was isolated and transferred to beaker containing Krebs solution (composition in $\mathrm{mM}$ : $\mathrm{NaCl}-136.9, \mathrm{KCl}-5.4$, Glucose - 5.5, $\mathrm{NaHCO}_{3}-23.8, \mathrm{MgCl}_{2}-1, \mathrm{CaCl}_{2}-1.5$, and EDTA-0.003), equilibrated with $95 \% \mathrm{O}_{2}$ and $5 \% \mathrm{CO}_{2}$. The beaker was placed in the water bath at $37^{\circ} \mathrm{C}$.

The procedure of [12] and coworkers (2009) with some modifications was followed to study the vascular reactivity in the isolated aorta. Two stainless steel wires were carefully inserted into lumen of the aortic rings. One wire was anchored to the hook at the base of an organ bath (Model 166051, Radnoti, Monrovia Ca, USA) and other wire was connected to force transducer (MLT0201/RAD 5 mg - 25 mg, AD instruments, Sydney, Australia) coupled to the transbridge amplifier (ML 224, Quad Bridge Amp, AD instruments). Data was acquired with a PowerLab Data Acquisition System (ML 870, Power Lab, AD instruments) using the chart software (Version 7) for measurement of isometric tension. The degree of contraction and relaxation were indicated by the tension development in the recording system and expressed in gram.

Rings were allowed to equilibrate for 60 minutes at a resting tension of 2 grams with changes of buffer every 15 minutes. When the isometric tension had stabilized, inhibitory concentration-response curves of the $\mathrm{SO}_{2}$ derivatives "1:3 $\mathrm{M} / \mathrm{M} \mathrm{NaHSO}{ }_{3}$ and $\mathrm{Na}_{2} \mathrm{SO}_{3}$ " (3 mM - 9 $\mathrm{mM}$ ) were constructed against contractions induced with phenylephrine $\left(\mathrm{PE} ; 1 \times 10^{-6} \mathrm{M}\right)$.

To detect the role of endothelial cells in the relaxant effect of $\mathrm{SO}_{2}$ derivatives, sandwich preparations were made similar to those described by [13], in which the endothelial layer in a long segment of the aorta was removed by gently rubbing the intimal surface of the rings with a syringe needle covered by a piece of cotton. The endothelium-denuded segment was then cut into several pieces; each piece was tested to confirm the removal of the endothelium by the lack of any response to acetylcholine $\left(1 \times 10^{-5} \mathrm{M}\right)$ following the pre-constriction with PE $\left(1 \times 10^{-6} \mathrm{M}\right)$.

The role of endothelium/NO, cGMP, $\mathrm{PGI}_{2}$ and epoxyeicosatreinoic acid (EET) in association with vasorelaxation induced by $\mathrm{SO}_{2}$ derivatives were evaluated following incubation of endothelium-intact rings with, LNAME $\left(3 \times 10^{-4} \mathrm{M}\right)$, methylene blue $(3 \mathrm{mM})$, indomethacin $\left(3 \times 10^{-5} \mathrm{M}\right)$ or clotrimazole $\left(3 \times 10^{-5} \mathrm{M}\right)$, blockers of above mentioned factors respectively, for $10 \mathrm{~min}$ utes prior to application of PE.

The concentration-response curves were fitted with a Hill equation, from which the half maximal inhibitory concentration $\left(\mathrm{IC}_{50}\right)$ values were given as geometric mean with $95 \%$ confidence intervals $(95 \% \mathrm{CI})$. Maximum contractile responses to $\mathrm{SO}_{2}$ derivatives were calculated as a percentage of the contraction produced by $\mathrm{PE}$ and were expressed as the means \pm standard error of the mean (SEM). The tension produced by PE was defined as $0 \%$ relaxation, and the baseline tension before addition of vasoconstrictors were defined as $100 \%$ relaxation.

\section{Statistical Analysis}

The statistical analysis was performed using two-way analysis of variance (ANOVA) supported by Bonferroni test when carrying out pair wise comparison between the same doses of different groups [14]. P-value less than $0.05(\mathrm{P}<0.05)$ were considered as statistically significant. All the graph, calculation and statistical analyses were performed using GraphPad Prism software version 5.0 for Windows (GraphPad Software, San Diego, California, USA).

\section{RESULTS}

The cumulative addition of $\mathrm{SO}_{2}$ derivatives, at the plateau phase of the contraction induced by $\mathrm{PE}\left(10^{-6} \mathrm{M}\right)$ in rats thoracic aortic rings caused contraction-dependent inhibition of the PE-induced contraction, in both, endothelium-intact and endothelium-denuded preparation (Figure 1). Endothelium denudation significantly $(\mathrm{P}<0.05)$ induced relaxation only at a dose $(7 \mathrm{mM})$ with $\mathrm{IC}_{50} 6.11$ $\mathrm{mM}$ (with $\mathrm{IC}_{50}$ of CI $95 \% 5.302$ to $6.919 \mathrm{mM}$ ) and 6.21 $\mathrm{mM}$ (with $\mathrm{IC}_{50}$ of CI $95 \% 5.845$ to $6.574 \mathrm{mM}$ ) in the denuded and intact endothelial rings, respectively. The $E_{\max }$ for endothelium denuded and intact rings were $83.13 \% \pm 14.755 \%$ and $62.026 \% \pm 6.527 \%$, respectively, 
as shown in (Table 1).

Inclusion of aortic rings with L-NAME did not alter dilation from control, however this response tended towards significance in precontracted rings with indomethacin, clotrimazole and methylene blue with an $\mathrm{IC}_{50}$ 's of $4.801 \mathrm{mM}$ (with an $\mathrm{IC}_{50}$ of CI $95 \%$ between 4.523 to $5.079), 5.331 \mathrm{mM}$ (4.868 to 5.795) and $4.011 \mathrm{mM}$ (3.846 to 4.176 ), and $E_{\max }$ were increased to $101.1 \% \pm 6.537 \%$, $66.92 \pm 7.538$ and $104.68 \pm 3.575$ respectively, as shown in (Figures 2-6 and Table 1).

\section{DISCUSSION}

It is well known that the endothelium plays an important role in the regulation of vascular tone by synthesis and release of endothelium-derived relaxing factors, including $\mathrm{NO}, \mathrm{PGI}_{2}$ and EDHF. Thus, it was decided to investigate role of endothelium and EDRFs involved in $\mathrm{SO}_{2}-$ induced responses.

The results of the present study demonstrated that removal of functional endothelium increased the relaxation response to $\mathrm{SO}_{2}$ only at high dose $(7 \mathrm{mM})$, indicating that vasorelaxation of $\mathrm{SO}_{2}$ may be inhibited by substances released by endothelium. This effect may be due to antagonistic actions of $\mathrm{PGI}_{2}$, EET and soluble gualanyl cyclase, because when aortic rings preincubated with either blockers an increment of $\mathrm{SO}_{2}$-induced vasorelaxation were observed. In this experiment, after the aortic rings were preincubated with indomethacin, the vasodilator effect caused by exogenous $\mathrm{SO}_{2}$ derivatives was enhanced in part. The $\mathrm{PGI}_{2}$ route might be one of the antagonistic mechanisms of the vasorelaxation caused by $\mathrm{SO}_{2}$ derivatives, because the preincubation with indomethacin caused only in part an enhancement of the aortic relaxation. Although, their was no previous study to explain the relation between $\mathrm{SO}_{2}$ and EET, [15] reported that $\mathrm{SO}_{2}$ might be a type of EDHFs, because it shares several features with EDHFs, furthermore, [16] concluded that within a physiological relevant concentration range, might induce a release of EDHF from vascular endothelium, but they didn't explained the effect of EET on $\mathrm{SO}_{2}$.

On the other hand, the results showed that the vasodilatory effects of $\mathrm{SO}_{2}$ derivatives could be not inhibited by treating aortic rings with L-NAME, it proved that the vasodilatory effect of $\mathrm{SO}_{2}$ was not mediated by NO. The same results concerning the relation between $\mathrm{SO}_{2}$ and NO were observed by [7]. The results of this study concluded that endothelium denudation and blocking of endothelium derived-relaxation factors enhanced vasodilator effect of $\mathrm{SO}_{2}$; this may elucidate the role of en-

Table 1. The $\mathrm{IC}_{50}\left(\mathrm{IC}_{50}\right.$ of CI 95\%) and $E_{\max } \pm \mathrm{SEM}$ for the effect of $\mathrm{SO}_{2}$ derivatives on control and preincubated aortic rings with L-NAME, indomethacin, clotrimazole and methylene blue.

\begin{tabular}{|c|c|c|c|c|c|c|}
\hline \multirow{2}{*}{$\begin{array}{l}\text { Relaxation } \\
\text { parameters }\end{array}$} & \multicolumn{6}{|c|}{ Treatments } \\
\hline & Control & Denuded aorta & $\begin{array}{c}\text { L-NAME } \\
\left(3 \times 10^{-4} \mathrm{M}\right)\end{array}$ & $\begin{array}{c}\text { Indomethacin } \\
\left(3 \times 10^{-5} \mathrm{M}\right)\end{array}$ & $\begin{array}{l}\text { Clotrimazole } \\
\left(3 \times 10^{-5} \mathrm{M}\right)\end{array}$ & $\begin{array}{l}\text { Methylene blue } \\
\qquad(3 \mathrm{mM})\end{array}$ \\
\hline $\mathrm{IC}_{50}$ & 6.21 & 6.11 & 5.898 & 4.801 & 5.331 & 4.011 \\
\hline $95 \% \mathrm{CI}-\mathrm{IC}_{50}$ & 5.845 TO 6.574 & 5.302 TO 6.919 & 5.397 TO 6.399 & 4.523 TO 5.079 & 4.868 TO 5.795 & $3.846 \mathrm{TO} 4.176$ \\
\hline$E_{\max }(\%)$ & $62.026 \pm 6.527$ & $83.13 \pm 14.755$ & $70.73 \pm 9.572$ & $101.1 \pm 6.537$ & $66.92 \pm 7.538$ & $104.68 \pm 3.575$ \\
\hline
\end{tabular}

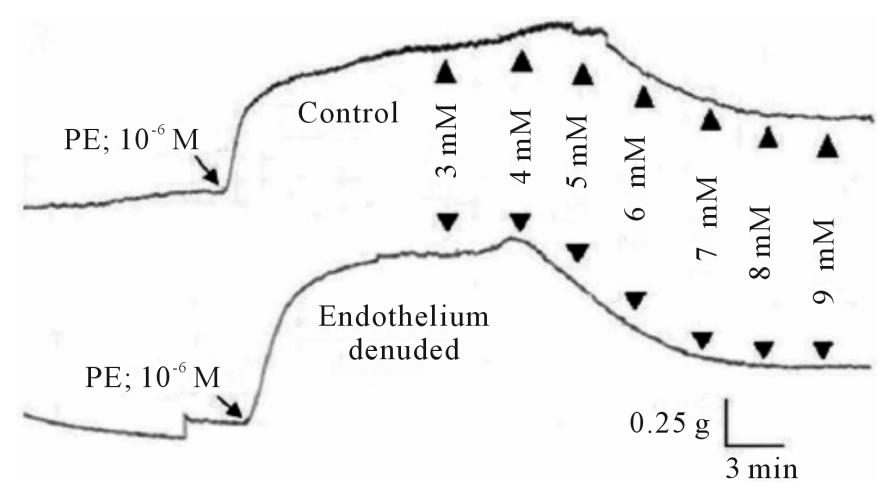

(a)

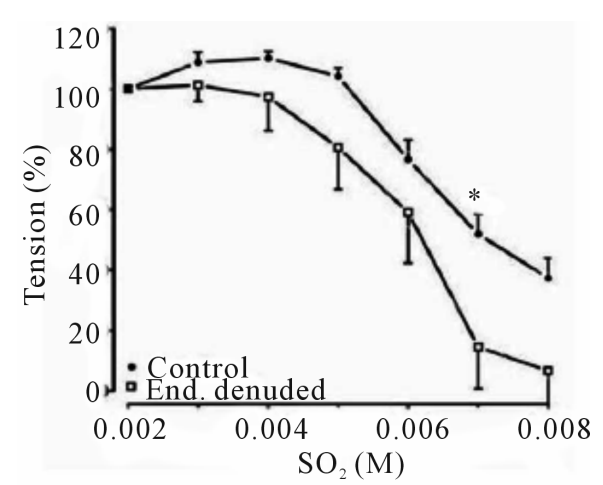

(b)

Figure 1. Concentration-response effects of $\mathrm{SO}_{2}$ on $\mathrm{PE}(1 \mu \mathrm{M})$-induced vasoconstriction. (a) Typical chart view trace; and (b) Dose-response curve showing comparative vasorelaxation effects of $\mathrm{SO}_{2}$ on $\mathrm{PE}$-induced vasoconstriction (control) and endothelium denuded aortic rings. $\boldsymbol{\Delta}$ indicates addition of $\mathrm{SO}_{2}(\mathrm{mM})$ in cumulative manner. $\left({ }^{*} \mathrm{p}<0.05\right.$; compared to control; Two-way ANOVA, Bonferroni post test). 


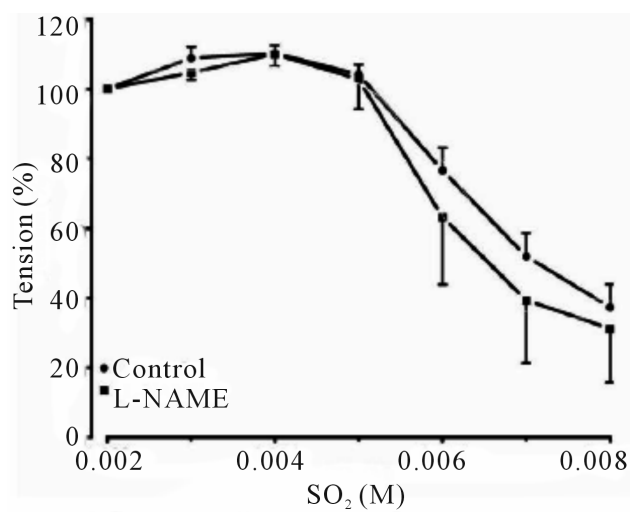

Figure 2. Cumulative dose-response curve for the vasorelaxant effects of $\mathrm{SO}_{2}$ on control and preincubated aortic rings with L-NAME $\left(3 \times 10^{-4}\right.$ $\mathrm{M})$, precontracted with PE $\left(10^{-6} \mathrm{M}\right)$.

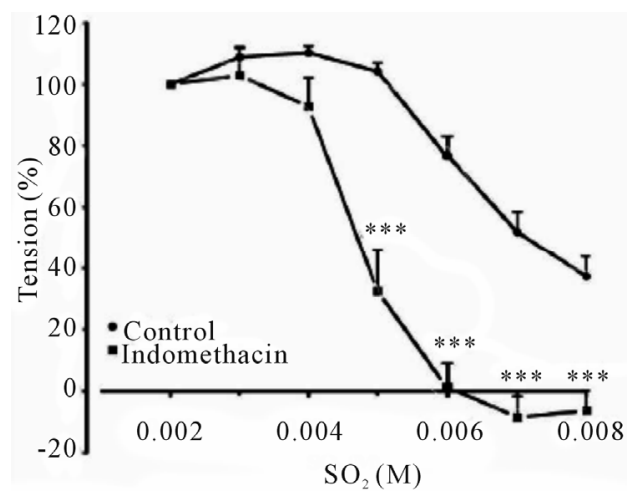

Figure 3. Cumulative dose-response curve for the vasorelaxant effect of $\mathrm{SO}_{2}$ on control and preincubated aortic rings with indomethacin $(3 \times$ $\left.10^{-5} \mathrm{M}\right)$, precontracted with PE $\left(10^{-6} \mathrm{M}\right) .\left({ }^{* * *} \mathrm{p}<\right.$ 0.001, compared to control; Two-way ANOVA, Bonferroni post test).

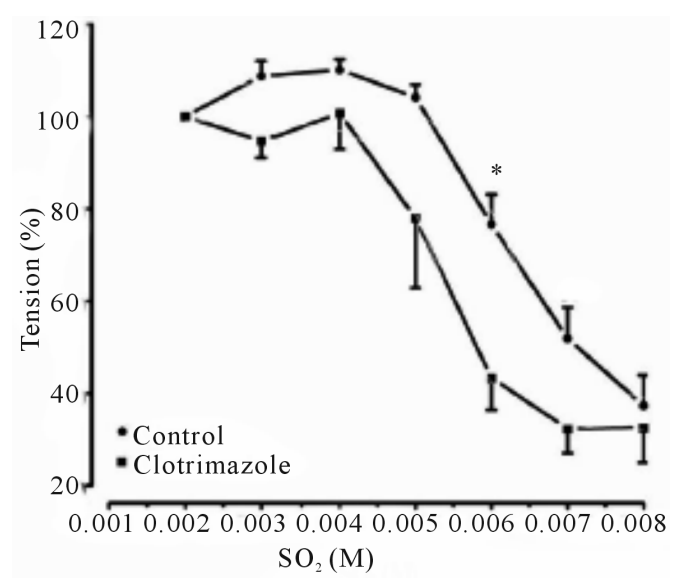

Figure 4. Cumulative dose-response curve for the vasorelaxant effects of $\mathrm{SO}_{2}$ on control and preincubated aortic rings with clotrimazole $\left(3 \times 10^{-5} \mathrm{M}\right)$, precontracted with PE $\left(10^{-6} \mathrm{M}\right) .\left(^{*} \mathrm{p}<0.05\right.$; compared to control; Two-way ANOVA, Bonferroni post test).

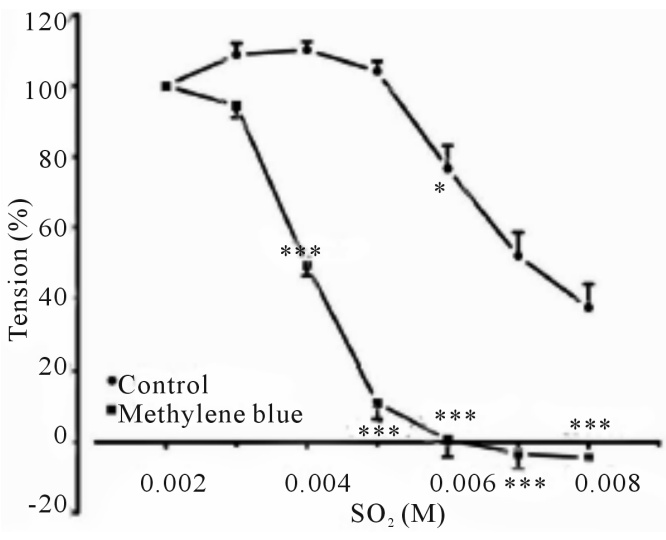

Figure 5. Cumulative dose-response curve for the vasorelaxant effects of $\mathrm{SO}_{2}$ on control and preincubated aortic rings with Methylene blue $(3 \mathrm{mM})$, precontracted with PE $\left(10^{-6} \mathrm{M}\right) .\left({ }^{* * *} \mathrm{p}<0.001\right.$; compared to control; Two-way ANOVA, Bonferroni post test).

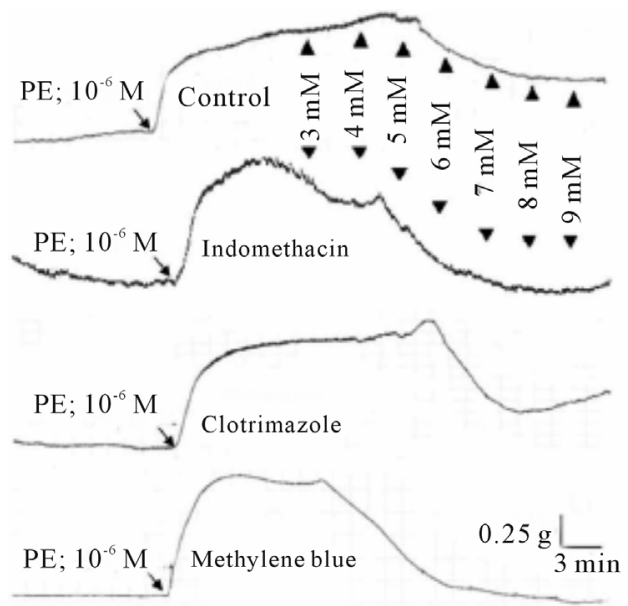

Figure 6. Typical chart view trace of concentration-response effects of $\mathrm{SO}_{2}$ on $\mathrm{PE}(1 \mu \mathrm{m})$-induced vasoconstriction, showing comparative vasorelaxant effects of $\mathrm{SO}_{2}$ (control) and indomethacine $\left(3 \times 10^{-5} \mathrm{M}\right)$, clotrimazole $\left(3 \times 10^{-5} \mathrm{M}\right)$, and methylene blue $(3 \mathrm{mM})$, preincubated aortic rings, respectively. $\boldsymbol{\Delta}$ indicates addition of $\mathrm{SO}_{2}(\mathrm{mM})$ in cumulative manner.

dothelium in the vasodilatory mechanism of $\mathrm{SO}_{2}$.

\section{REFERENCES}

[1] Adams, D.J. and Hill, M.A. (2004) Potassium channels and membrane potential in the modulation of intracellular calcium in vascular endothelial cells. Journal of Cardiovascular Electrophysiology, 15, 13. http://dx.doi.org/10.1046/j.1540-8167.2004.03277.x

[2] Zhang, D. (2007) Hydroperoxide-induced oxidative stress in the arterial wall: Pharmacological characterization of the effects on arterial contractility. Academic Thesis, Eberhard Karls Universität Tübingen. 
[3] Nie, A. and Meng, Z. (2005) Study of the interaction of sulfur dioxide derivative with cardiac sodium channel. Biochimica et Biophysica Acta, 1718, 7. http://dx.doi.org/10.1016/j.bbamem.2005.09.020

[4] Meng, Z., Qin, G., Zhang, B. and Bai, J. (2004) DNA damaging effects of sulfur dioxide derivatives in cells from various organs of mice. Mutagenesis, 19, 4. http://dx.doi.org/10.1093/mutage/geh058

[5] Nie, A. and Meng, Z. (2007) Sulfur dioxide derivatives modulate $\mathrm{Na} / \mathrm{Ca}$ exchange currents and cytosolic $\left[\mathrm{Ca}^{2+}\right]_{\mathrm{i}}$ in rat myocytes. Biochemical and Biophysical Research Communications, 358, 6. http://dx.doi.org/10.1016/j.bbrc.2007.05.008

[6] Li, J. and Meng, Z. (2009) The role of sulfur dioxide as an endogenous gaseous vasoactive factor in synergy with nitric oxide. Nitric Oxide, 20, 166-174. http://dx.doi.org/10.1016/j.niox.2008.12.003

[7] Meng, Z., Li, Y. and Li, J. (2007) Vasodilatation of sulfur dioxide derivatives and signal transduction. Archives of Biochemistry and Biophysics, 467, 291-296. http://dx.doi.org/10.1016/j.abb.2007.08.028

[8] Du, X., Zhang, C., Jin, H., Du, J. and Tang, C. (2006) Vasorelaxant effect of sulfur dioxide derivatives on isolated aortic rings of rats and its mechanisms. Journal of Peking University, 38, 581-585.

[9] Du, Z., Zhou, Y. and Yang, P. (2007) Sulfur dioxide derivatives increase a hyperpolarization-activated inward current in dorsal root ganglion neurons. Toxicology, 239, 180-185. http://dx.doi.org/10.1016/j.tox.2007.07.005

[10] Nie, A. and Meng, Z. (2005) Sulfur dioxide derivative modulation of potassium channels in rat ventricular myocytes. Archives of Biochemistry and Biophysics, 442, 187-195. http://dx.doi.org/10.1016/j.abb.2005.08.004

[11] Zhang, Q. and Meng, Z. (2009) The vasodilator mechanism of sulfur dioxide on isolated aortic rings of rats: Involvement of the $\mathrm{K}^{+}$and $\mathrm{Ca}^{2+}$ channels. European Journal of Pharmacology, 602, 117-123. http://dx.doi.org/10.1016/j.ejphar.2008.11.030

[12] Aziz, N., Malik, H., Safur, R., Samra, B., Sidra, R. and Anwar, H. (2009) Antihypertensive, antioxidant, antidyslipidemic and endothelial modulating activities of a polyherbal formulation (POL-10). Vascular Pharmacology, 50, 8. http://dx.doi.org/10.1016/j.vph.2008.09.003

[13] Dong, H., Gareth, J., Denise, G., William, C. and Christopher, R. (1997) NO/PGI2-independent vasorelaxation and the cytochrome $\mathrm{P} 450$ pathway in rabbit carotid artery. British Journal of Pharmacology, 120, 695-701. http://dx.doi.org/10.1038/sj.bjp.0700945

[14] Motulsky, H. and Christopolous, A. (2003) GrdaphPad Prism: Fitting models to biological data using linear and non-linear regression; a practical guide to curve fitting. GraphPad Software, Inc.

[15] Liu, D., Jin, H., Tang, C. and Du, J. (2010) Sulfur dioxide: A novel gaseous signal in the regulation of cardiovascular functions. Mini-Reviews in Medicinal Chemistry, 10, 10391045. http://dx.doi.org/10.2174/1389557511009011039

[16] Meng, Z., Li, J., Zhang, Q., Bai, W., Yang, Z., Zhao, Y. and Wang, F. (2009) Vasodilator effect of gaseous sulfur dioxide and regulation of its level by Ach in rat vascular tissues. Inhalation Toxicology, 21, 1223-1228. 